\title{
Direct measurements of sugar uptake from seawater into molluscan larvae
}

\author{
John R. Welborn, Donal T. Manahan \\ Department of Biological Sciences, University of Southern California, Los Angeles, California 90089-0371, USA
}

\begin{abstract}
A method for the direct measurement of picomole amounts of mono-, di-, and trisaccharides in seawater was developed by combining high-performance liquid chromatography (HPLC) with amperometric detection. This new method is described and then applied to the study of sugar uptake from seawater into veliger larvae of a bivalve (Crassostrea gigas) and a gastropod (Haliotis rufescens). Bivalve veligers take up glucose, maltose, cellobiose, and cellotriose but not L-rhamnose, isomaltose, maltotriose, or isomaltotriose. Similarly, gastropod veligers take up glucose and maltose, but not L-rhamnose or maltotriose. Glucose and maltose are transported into the bivalve veligers by separate pathways and the influx of ${ }^{14} \mathrm{C}$-labeled glucose is a good measure of the net flux (measured by HPLC). The uptake of complex sugars, in addition to monosaccharides, permits molluscan larvae to utilize a greater part of the dissolved organic material in the sea as a source of nutrition
\end{abstract}

\section{INTRODUCTION}

Most studies on the transport of dissolved organic matter (DOM) from seawater by soft-bodied marine invertebrates have focused primarily upon the flux of free amino acids (e.g. Stephens \& Schinske 1961, Ferguson 1967, Davis \& Stephens 1984, Manahan 1989). There is also a smaller body of literature that shows invertebrates can transport other classes of compounds such as sugars (e.g. Stephens 1962, Ahearn \& Gomme 1975, Pajor et al. 1989), fatty acids (Testerman 1972), acetate (Holst \& Zebe 1984), and nucleosides (Schneider \& Whitten 1987). About $10 \%$ of the constituents in the total DOM pool have been chemically identified (Williams 1975); of this fraction only a small percentage can be quantified due to limitations in analytical chemistry. Thus, it is necessary to develop analytical methods that permit the measurement of other classes of compounds in seawater. Such advances are needed to better understand the role of DOM in the nutrition of marine invertebrates.

Two experimental approaches have been used to determine if organic compounds can be transported by marine invertebrates from seawater. The first uses radiolabeled substrates to measure either the increase in radioactivity within the organism, or the decrease of radioactivity (influx) in the medium (Stephens 1962). This approach is sensitive and relatively easy to per- form but gives no information on net flux of the compound under study (Johannes et al. 1969, Manahan 1989). The second approach measures the compound of interest in seawater (Manahan et al. 1982) and monitors the subsequent changes in concentration with time (net flux). This approach has the advantage of yielding information on net flux, but is dependent upon advances in analytical chemistry. Both of these approaches have been successfully used in studies of amino acid transport, but only the former has been extensively employed for studies of sugar transport (Stephens 1962, Pajor et al. 1989).

The direct quantification of sugars in seawater by high-performance liquid chromatography (HPLC) has been confounded by analytical problems. Conventional detection methods for sugars, such as refractive index or ultraviolet detection, lack the sensitivity to measure these compounds in natural seawater at submicromolar concentrations. The low concentration of sugars in seawater has forced investigators to concentrate their samples either by rotary evaporation or air drying (Mopper et al. 1980, Ittekkot et al. 1981). However, quantification is difficult with all of these methods because pretreatment procedures can lead to unpredictable losses of material (Dawson \& Mopper 1978). In the present study, we describe a series of modifications to an analytical procedure (cf. Watanabe 1985) that permits the quantification of individual sugars at sub- 
micromolar concentrations in seawater. No desalting or concentrating of samples is required. In this paper we use this method to study sugar uptake from seawater by molluscan larvae.

\section{MATERIALS AND METHODS}

Reagents and sugar standards. Pure water for HPLC analysis was made by distilling deionized water and then removing organic material by intense UV oxidation (Organicpure, Sybron \& Barnstead). HPLC-grade methanol and acetonitrile were purchased from Baxter Healthcare Corp. (Burdick \& Jackson division). All chemicals and standards were purchased from either Sigma Chemical Co. or Spectrum Chemical Co

HPLC quantification of individual sugars in seawater. For the analysis of sugars, a $500 \mu$ sample of seawater was taken and gently passed through a 0.2 $\mu \mathrm{m}$ (pore size) filter housed in a $13 \mathrm{~mm}$ diameter 'Pop top' (Nuclepore) holder. A $400 \mu$ sample of the filtrate was taken and $100 \mu$ of water was added. To this mixture was added $500 \mu$ of acetonitrile. This dilution factor of 2.5 was empirically determined to give the best peak symmetry while avoiding salt precipitation. A $100 \mu \mathrm{l}$ aliquot of this final solution was injected onto the HPLC column. Thus this injection volume contained $40 \mu \mathrm{l}$ of the original seawater sample. Sugars were separated isocratically using a mobile phase of $45 \%$ aqueous solvent and $55 \%$ acetonitrile. The aqueous solvent was a solution of $2.7 \% \mathrm{NaCl}(\mathrm{w} / \mathrm{v})$. The addition of salt to the mobile phase was necessary to match the ionic concentration of the mobile phase to that of the injected seawater sample. Failure to do so resulted in a large solvent-front peak that masked most of the sugar peaks. A Waters Model 6000A pump and a Rainin aminopropyl-bonded silica (particle size $5 \mu \mathrm{m}$ ) column (250 $\mathrm{mm}$ by $4.6 \mathrm{~mm}$ ), with a guard column of the same packing, were used for the separation of the sugars. The sample injection valve was a Rheodyne Model 7010, fitted with a $100 \mu$ sample loop. The post-column reagent pump was a Waters Model M45 equipped with a SSI (Scieritific Systems) Model LP-21 diaphragm pulse dampener. The pulse dampener was connected to a stainless steel mixing tee with $6 \mathrm{~m}$ of stainless steel tubing of $1 / 16^{\prime \prime}(1.6 \mathrm{~mm})$ outside diameter and $0.005^{\prime \prime}(0.13 \mathrm{~mm})$ internal diameter. The combination of the pulse dampener and the small diameter of the stainless steel tubing provided the necessary back pressure to reduce pulsations from the reagent pump.

Sugars were detected with a post-column reaction technique (Watanabe \& Inoue 1983) involving an electrochemical mediator, copper (II) bis(phenanthroline) (CBP). Phenanthroline (570.8 mg, Sigma Chemical Co.) was dissolved in $5 \mathrm{ml}$ of methanol that was then added to a warm aqueous solution of copper acetate $(191.7 \mathrm{mg}$ in $300 \mathrm{ml}$ water). This solution contained a 3:1 molar ratio of phenanthroline to copper The excess phenanthroline ensured that all of the copper was complexed. The resulting solution was stirred on a hot plate until all the methanol had evaporated (ca 2 h). The CBP complex was then diluted to $960 \mathrm{ml}$ with water to give a final concentration of $1 \mathrm{mM}$ CBP, empirically determined to maximize sensitivity. Dibasic sodium phosphate (12.27 g. Spectrum Chemical) was added to the CBP solution and the $\mathrm{pH}$ was adjusted to 11.6 using a concentrated $\mathrm{NaOH}$ solution. The $\mathrm{CBP}$ reagent was filtered through a polycarbonate filter. Because acetonitrile partially dissolves polycarbonate, the mobile phase was filtered through a polyethylene filter. Both filter types were $0.2 \mu m$ pore size Nuclepore. The CBP reagent and the mobile phase were degassed (LKB Model 2156 Solvent Conditioner) with helium for at least $1 \mathrm{~h}$ immediately prior to use, and were kept under pressurized helium during all analyses.

Individual sugars were separated on the column and the CBP reagent was added by a mixing tee (postcolumn). A $2: 1$ ratio of eluent flow $\left(0.8 \mathrm{ml} \mathrm{min}^{-1}\right)$ to reagent flow $\left(0.4 \mathrm{ml} \mathrm{min}^{-1}\right)$ gave the best sensitivity and peak symmetry, Lowering this ratio resulted in an excessive dilution of the separated peaks by the postcolumn reagent, resulting in lower sensitivity and wider peaks. Increasing this ratio also resulted in decreased sensitivity, presumably because not enough CBP was present to react with the reducing sugars. The combined solutions were then pumped through an inline teflon reaction coil of $6.2 \mathrm{~m}$ length $\left[1 / 16^{\prime \prime}(1.6 \mathrm{~mm})\right.$ outside diameter by $0.01^{\prime \prime}(0.25 \mathrm{~mm})$ internal diameter]. The entire length of the reaction coil was knitted through $1 / 16^{\prime \prime}$ holes in an aluminum board. Interweaving the reaction coil through an aluminum board helped to maintain peak symmetry. The reaction coil was immersed in a water bath maintained at $98^{\circ} \mathrm{C}$ \pm 0.02 (Precision Model RDL 20), the maximum temperature that could be used without significant baseline shifts. A degassing period of at least 1 h was needed to avoid the formation of gas bubbles in the reaction coil at $98^{\circ} \mathrm{C}$. Also, it was important that the length of the reaction coil be at least $6.2 \mathrm{~m}$ to maintain high back pressure needed to keep the eluent in solution at the high temperatures of the reaction. The sugars in the eluent, under the conditions of high temperature $\left(98^{\circ} \mathrm{C}\right)$ and high $\mathrm{pH}(11.6)$, reduced the copper in the CBP complex from $\mathrm{Cu}^{+2}$ to $\mathrm{Cu}^{+1}$ The resulting zones of reduced $\mathrm{CBP}$ in the eluent stream were then reoxidized as they passed across the working electrode (glassy carbon) in the cell of the electrochemical detector (Model LC-4B, Bioanalytical Systems). The low applied potential $(40 \mathrm{mV})$ across the 
working electrode ensured that only the CBP was oxidized because organic materials require much higher potentials for oxidation. The resulting current from the reaction at the electrode was converted to voltage by the detector and recorded with a computing integrator. Individual sugars were identified by retention times compared to known standards. Quantification was performed by integrating peak areas using a Waters Model 740 Data Module.

Larvae. Veliger larvae of the bivalve Crassostrea gigas were supplied by Coast Oyster Co. (Quilcene, WA, USA). Veliger larvae of the gastropod Haliotis rufescens were provided by the 'Ab Lab' (Port Hueneme, CA, USA). Experiments with bivalve veligers were conducted at $20^{\circ} \mathrm{C}$; experiments with gastropod veligers at $17^{\circ} \mathrm{C}$.

Net uptake of sugars from seawater. Rates of net flux were determined by measuring the disappearance of substrates from seawater using HPLC. All seawater used for experiments was first passed through a $0.2 \mu \mathrm{m}$ (pore size) polycarbonate filter and then autoclaved. Immediately prior to an experiment, all larvae were collected on a mesh screen, washed with sterile seawater, and then resuspended in a graduated cylinder To determine the concentration of larvae, replicate aliquots were taken and the larvae were counted. Preliminary experiments revealed that concentrations of larvae ranging from 800 to $2800 \mathrm{ml}^{-1}$ were needed to produce a rate of sugar uptake that was measurable by HPLC (see figure legends for exact numbers). A mixture of sugars was added to a $50 \mathrm{ml}$ flask (experiments shown in Fig. 2) or a $20 \mathrm{ml}$ vial (experiments shown in Figs. 3 and 4 ) at the start of the experiment to give a final substrate concentration of ca $1 \mu \mathrm{M}$ for each sugar. Samples of the seawater $(500 \mu l)$ were taken at various time intervals for HPLC analysis. Each sample was gently passed through a $0.2 \mu \mathrm{m}$ (pore size) filter and frozen at $-70^{\circ} \mathrm{C}$ for later analysis. No differences were observed between sugar standards which had been filtered then frozen at $-70^{\circ} \mathrm{C}$ for 4 mo and freshly prepared standards. Nonetheless, all analyses were completed within $14 \mathrm{~d}$ of taking the samples.

Net flux and influx of glucose. Isotopic techniques and HPLC analyses were combined to compare the net flux and influx of glucose into veliger larvae of Crassostrea gigas. Larvae were exposed to a concentration of $900 \mathrm{nM}$ glucose which was comprised of ${ }^{14} \mathrm{C}$-glucose (353 $\mu \mathrm{Ci} \mu_{\mathrm{mol}}^{-1}$, Sigma Chemical Co.) and unlabeled glucose. A series of $500 \mu \mathrm{l}$ samples was taken during a time course experiment, of which $400 \mu \mathrm{l}$ was used for HPLC analysis and $20 \mu \mathrm{l}$ for isotope counting. The sample of the filtrate used to determine the rate of depletion of ${ }^{14} \mathrm{C}$-glucose (influx) was placed in a scintillation vial with $50 \mu \mathrm{l}$ of concentrated $\mathrm{HCl}$. The acid converts all dissolved bicarbonate to $\mathrm{CO}_{2}$, thus remov- ing any ${ }^{14} \mathrm{CO}_{2}$. After $24 \mathrm{~h}, 5 \mathrm{ml}$ of scintillation cocktail (Scintiverse, Fisher Scientific Co.) were added to each vial. The amount of radioactivity in each vial was determined by liquid scintillation counting (LKB model 1211). The decrease of radioactivity in the seawater was used to determine glucose influx. The decrease in the total concentration of glucose (HPLC analyses) was used to determine net flux.

Effect of maltose on the transport rate of ${ }^{14} \mathrm{C}$-glucose by larvae. Veliger larvae of Crassostrea gigas were collected, washed, resuspended, and counted as described above. The rate of transport of ${ }^{14} \mathrm{C}$-glucose by larvae from a $1 \mu \mathrm{M}$ solution was determined in the absence and presence of $200 \mu \mathrm{M}$ maltose. A known number of larvae $\left(636 \mathrm{ml}^{-1}\right)$ was added to each of 3 vials containing $2 \mu \mathrm{Ci}$ of ${ }^{14} \mathrm{C}$-glucose and unlabeled glucose $(10 \mathrm{ml}$ of seawater, final glucose concentration was $1 \mu \mathrm{M}$ ). Identical experiments were set up in an additional 3 vials, except that maltose was also added (i.e. glucose: $1 \mu \mathrm{M}$, maltose: $200 \mu \mathrm{M}$ ). A time course experiment (duration 8 to $10 \mathrm{~min}$ ) was performed with each vial during which $500 \mu \mathrm{l}$ samples of the seawater containing larvae were taken at 1 min intervals. The larvae were separated from the seawater by centrifugation through silicone oil, and the radioactivity per larva determined using procedures described elsewhere (Manahan 1989). The amount of radioactivity per larva was corrected for the change in specific activity due to the addition of unlabeled glucose and the transport rate was calculated as fmol glucose larva ${ }^{-1} \mathrm{~h}^{-1}$.

\section{RESULTS}

Fig. 1A shows an original chromatogram of the separation of 5 sugars added to natural seawater, each present at $1 \mu \mathrm{M}$ (40 pmol injected). The sugars in seawater were measured directly with no pretreatment, other than matching the injected sample to the mobile phase as described above. The 5 sugars were separated and quantified in ca $3 \mathrm{~min}$. The order of elution is $\mathrm{L}$ rhamnose (monosaccharide), glucose (monosaccharide), maltose (disaccharide), melibiose (disaccharide), and maltotriose (trisaccharide). Sugars are separated by normal-phase chromatography and the retention times are related to the number and position of the hydroxyl groups. The detector response was directly proportional to the amount of glucose injected (Fig. 1B).

\section{Net uptake of sugars by larvae}

Fig. 2A shows the change in concentration of 4 sugars in the presence of veliger larvae of Crassostrea gigas. Maltotriose and rhamnose were not taken up, 

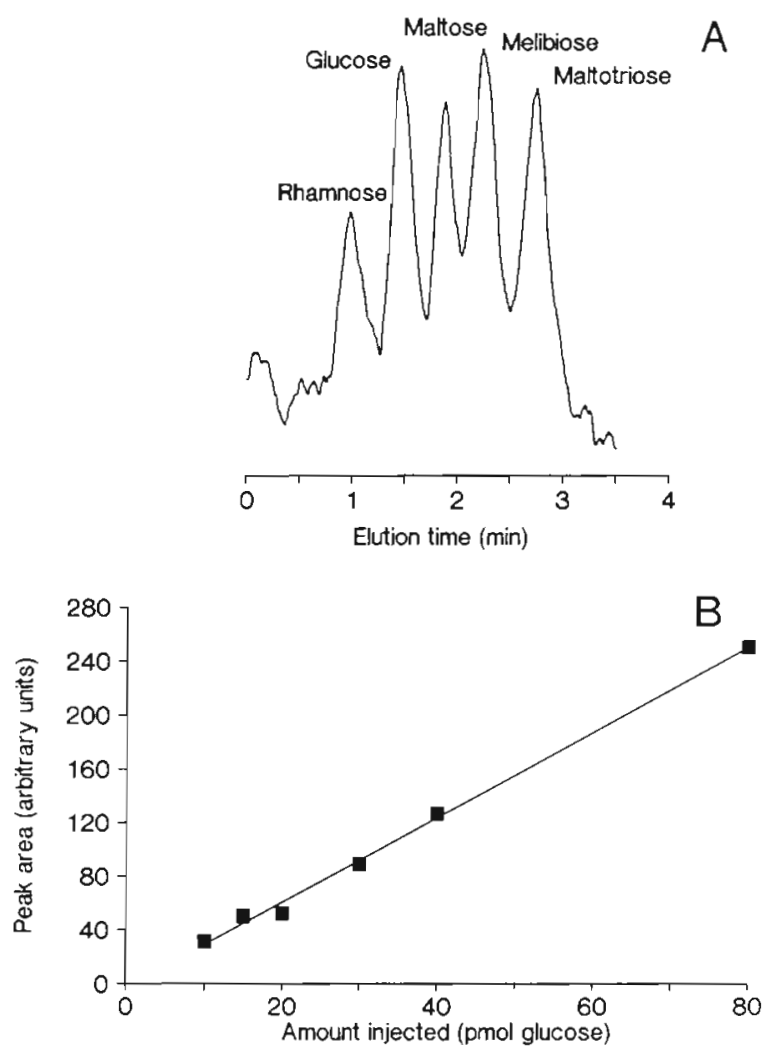

Fig. 1. (A) Chromatogram showing the separation by HPLC of 5 sugars added to seawater (each peak 40 pmol). (B) Linear increase in peak area (in arbitrary units, volts) as a function of the amount of glucose injected per sample of seawater. The $r^{2}$

value for the least-squares linear regression was 0.99

while both glucose and maltose were completely removed (i.e. below the limit of detection) within 240 min. No significant changes in concentration were measured for these same 4 sugars in the control flask (no larvae) after $300 \mathrm{~min}$ (Fig. 2A, inset). A similar pattern of net uptake was observed for veliger larvae of Haliotis rufescens (Fig. 2B). Glucose and maltose were completely removed in $240 \mathrm{~min}$, while there was no detectable uptake of maltotriose or rhamnose.

A range of other complex sugars was tested to see if larvae of Crassostrea gigas had the capacity to transport them. Larvae were exposed to the disaccharides cellobiose and isomaltose, and the trisaccharides cellotriose and isomaltotriose. Fig. 3A shows that larvae can take up cellobiose in addition to glucose but not isomaltose or maltotriose. In this experiment, glucose was completely removed to the limit of detection by $90 \mathrm{~min}$. Cellobiose was taken up more slowly and was completely removed by $180 \mathrm{~min}$. Larvae also took up the trisaccharide cellotriose, but at a lower rate than glucose (Fig. 3B). Larvae did not take up the trisaccharide isomaltotriose (Fig. 3B).

Fig. 4 illustrates the relationship for larvae of Cras-
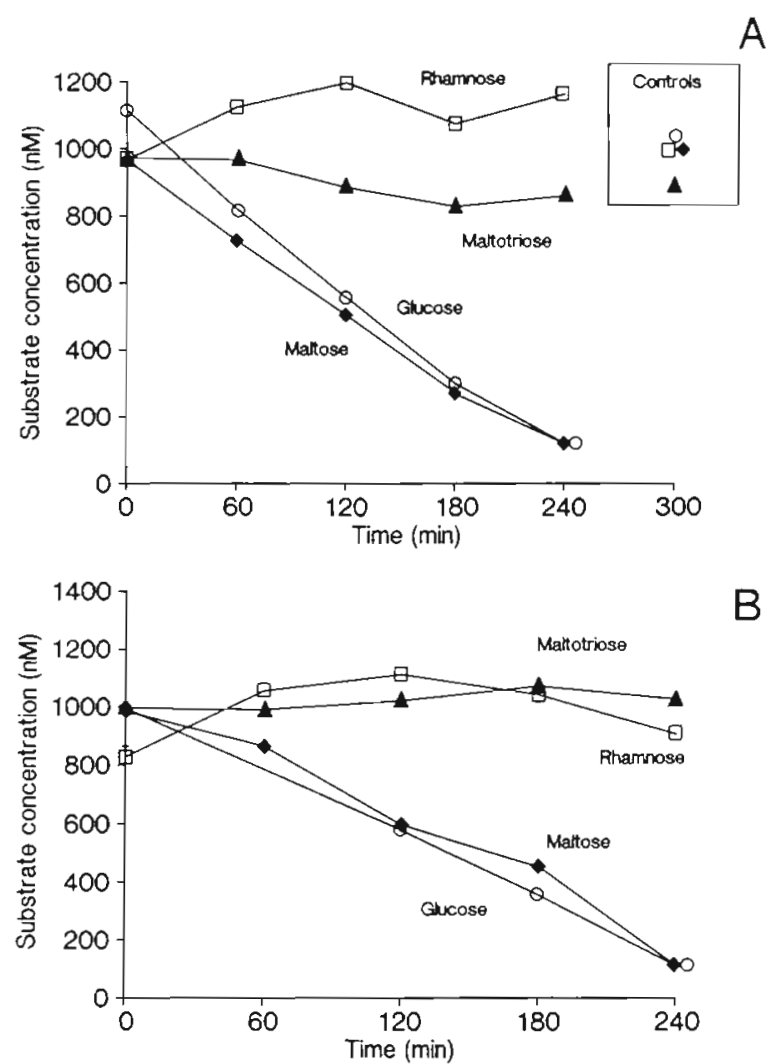

Fig. 2. (A) Crassostrea gigas. Uptake of sugars from seawater by veliger larvae (152 $\mu \mathrm{m}$ valve length, $2807 \mathrm{ml}^{-1}$ ) as measured by HPLC. Inset: results of a separate experiment in which the same sugars were measured in seawater after $5 \mathrm{~h}$, but with no larvae present (control). (B) Haliotis rufescens.

Uptake of sugars by veliger larvae ( $5 \mathrm{~d}$ old, $\left.786 \mathrm{ml}^{-1}\right)$

sostrea gigas between the rates of glucose net flux, as measured with HPLC, and the rates of influx, as measured with ${ }^{14} \mathrm{C}$-label. The rate of isotope influx was a good measure of the rate of glucose net flux into larvae.

\section{Effect of maltose on the rate of transport of ${ }^{14} \mathrm{C}$-glucose by larvae}

Fig. 2A shows that veligers of Crassostrea gigas can take up both glucose and maltose when both substrates were present in seawater. To resolve if maltose was being hydrolyzed and transported as glucose, an experiment was carried out to determine whether maltose and glucose were transported via the same carrier in larvae of $C$. gigas. The transport rate by larvae of ${ }^{14} \mathrm{C}$-glucose at $1 \mu \mathrm{M}$ in seawater was measured in the presence and absence of $200 \mu \mathrm{M}$ maltose. In 3 separate experiments, with no maltose present, ${ }^{14} \mathrm{C}$-glucose was transported at rates of 58,63 , and $76 \mathrm{fmol}$ glucose larva ${ }^{-1} \mathrm{~h}^{-1}$ (Table 1). These rates of glucose transport were not significantly different from those measured in the presence of $200 \mu \mathrm{M}$ maltose (see ANOVA, Table 1). 

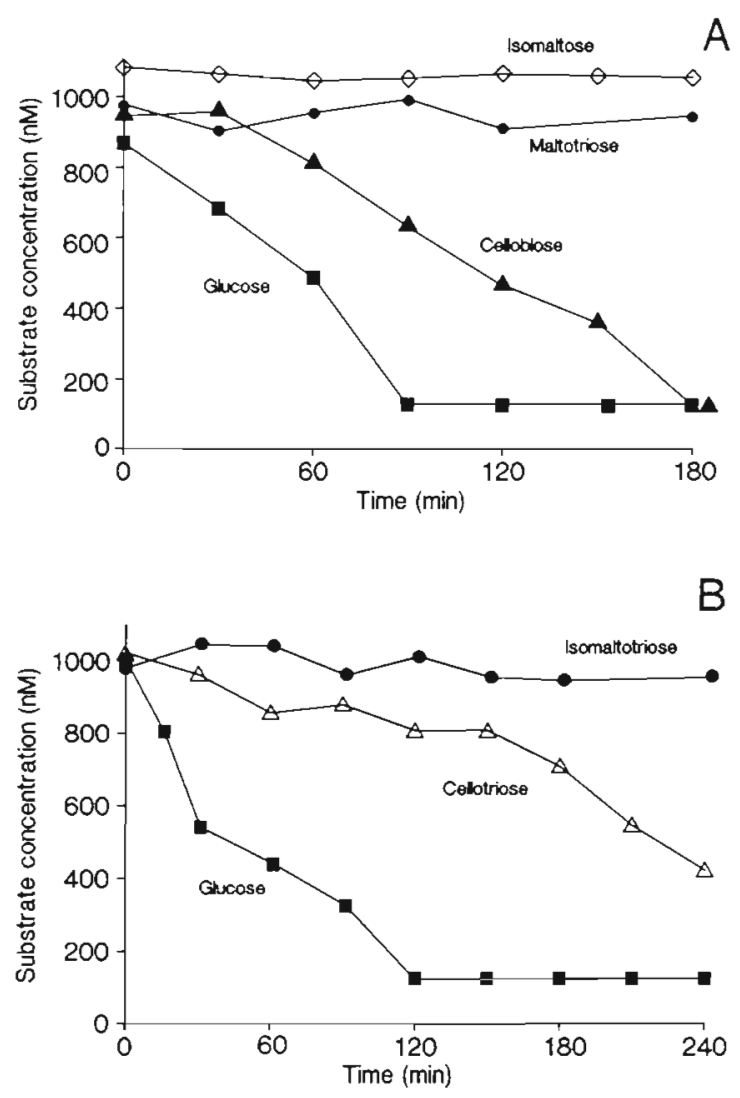

Fig. 3. Crassostrea gigas. Uptake of sugars by veliger larvae as measured by HPLC. (A) Veliger larvae (175 $\mu \mathrm{m}$ valve length, $\left.2200 \mathrm{ml}^{-1}\right)$. (B) Veliger larvae $\left(207 \mu \mathrm{m}\right.$ valve length, $2148 \mathrm{ml}^{-1}$ )

incubated in a different mixture of sugars to that of (A)

\section{DISCUSSION}

\section{Measurement of sugars in seawater}

The amperometric detection scheme of Watanabe (1985) allows for the measurement of individual sugars in pmol amounts. However, Watanabe's methods

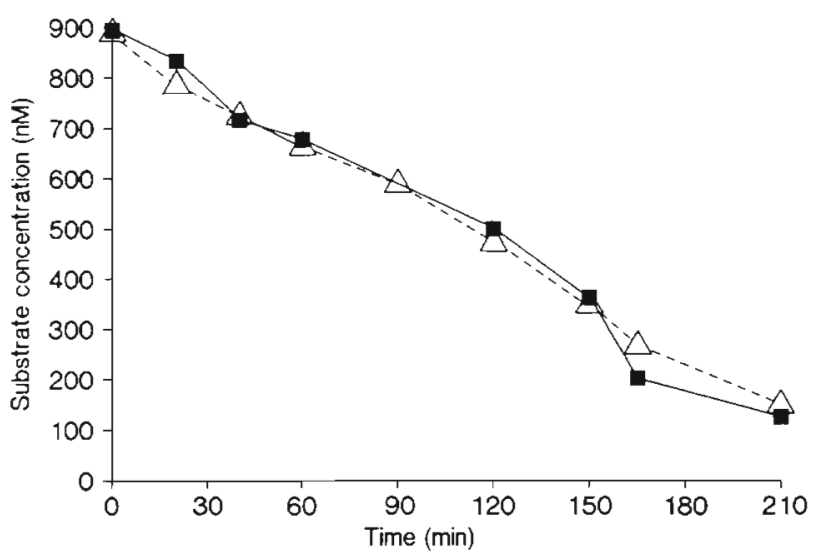

Fig. 4. Crassostrea gigas. Net flux (-: measured by HPLC) and influx ( $\Delta---\Delta$ : measured by ${ }^{14} \mathrm{C}$-label) of glucose into veliger larvae (152 $\mu \mathrm{m}$ valve length, $1530 \mathrm{ml}^{-1}$ )

require that samples be diluted 50- to 20000 -fold with mobile phase prior to HPLC analysis. Thus, his procedures, originally developed for analyzing fruit juices and human fluids, do not permit quantification of sugars at submicromolar concentrations in seawater. Our procedures overcame this limitation by using the following modifications: (1) adding $\mathrm{NaCl}$ to the mobile phase, (2) sparging the reagents with helium for at least $1 \mathrm{~h}$, (3) diluting the seawater sample by a factor of 2.5 with distilled water and acetonitrile before injection, (4) utilizing a brand of aminopropyl-bonded column that can separate sugars even when using a relatively low percentage (volume to volume) of acetonitrile, and (5) using a knitted coil for the reaction at $98^{\circ} \mathrm{C}$. With these modifications, as little as $5 \mathrm{pmol}$ of an individual reducing sugar can be detected in seawater without any sample concentration or desalting (Fig. 1). For the analyses presented here, with a $100 \mu$ injection volume (i.e. $40 \mu \mathrm{l}$ seawater), $5 \mathrm{pmol}$ equates to a $125 \mathrm{nM}$ concentration for each sugar. Lower sugar concentrations can be measured using larger injection vol-

Table 1. Crassostrea gigas. Effect of maltose on the transport rate of ${ }^{14} \mathrm{C}$-glucose by veliger larvae $\left(207 \mu \mathrm{m}\right.$ valve length, $\left.636 \mathrm{ml} \mathrm{l}^{-1}\right)$. Concentration of glucose, $1 \mu \mathrm{M}$; concentration of maltose, $200 \mu \mathrm{M}$. n: number of points used to calculate each value of $\mathrm{r}^{2}$

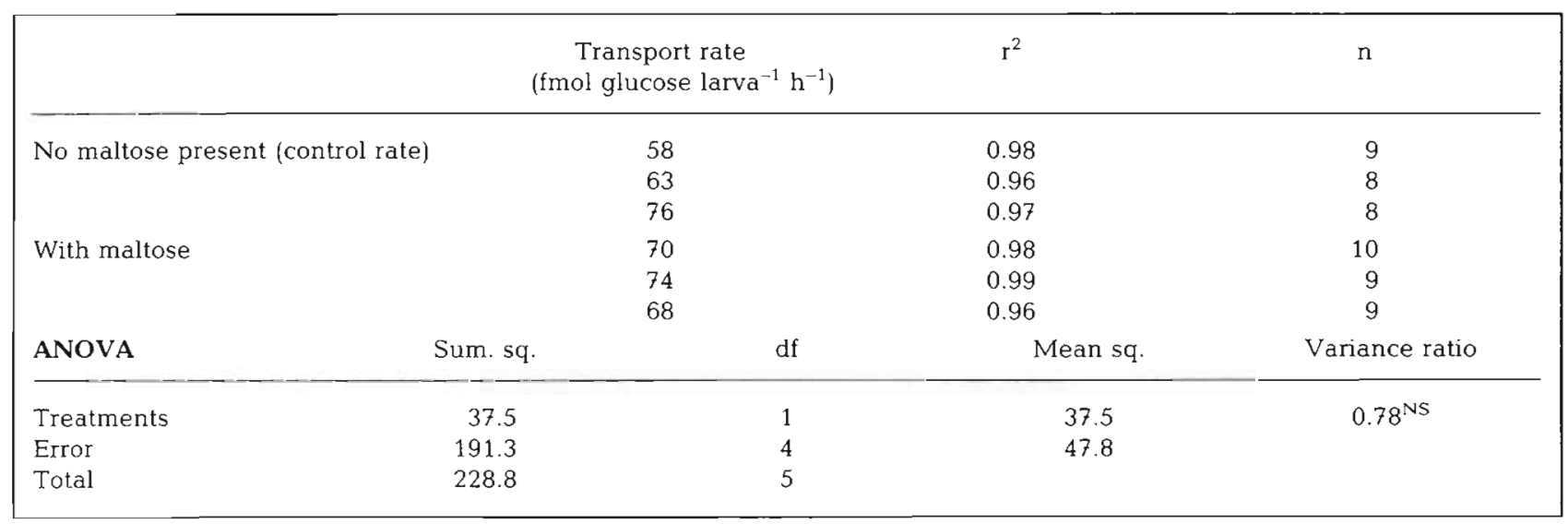


umes (e.g. a $250 \mu \mathrm{I}$ injection loop would allow detection of a sugar at $50 \mathrm{nM}$ ). However, we found that larger injection volumes often resulted in the compound of interest being eluted in a wider peak. Depending upon the compounds being measured, using larger injection volumes could make separations difficult. However, larger injection volumes should be tested for each specific application.

\section{Uptake of sugars from seawater by larvae}

Filtered seawater that had been sterilized by autoclaving was used as an incubation medium. Larvae were always thoroughly rinsed with this seawater prior to experiments. Thus, any bacteria in the experiments could only be those associated with the larvae. Bacteria-free (axenic) larvae of Crassostrea gigas (cf. Manahan 1989) were not used for the experiments presented here. However, no significant differences between axenic and xenic cultures have been observed for the transport rates of amino acids by larvae (Davis \& Stephens 1984, Jaeckle \& Manahan 1989). If bacteria were present in significant numbers in our experiments then the concentration of all sugars should decrease given the heterotrophic potential of bacterial populations (Williams 1975). However, of the monosaccharides tested (glucose and L-rhamnose) only glucose was taken up during our experiments. For the disaccharides, both maltose and cellobiose were taken up, but not isomaltose. Similarly, only cellotriose was taken up of the 3 trisaccharides tested. Because of this selective uptake of sugars, we are confident that the larvae were responsible for the observed patterns of sugar uptake.

The influx rate of radiolabeled-glucose into Crassostrea gigas larvae was similar to the rate of glucose net flux when the latter was measured by direct chemical analysis (HPLC) (Fig. 4). This finding supports other reports for marine invertebrates that have used ${ }^{14} \mathrm{C}$-glucose to measure influx (e.g. Stephens 1962) or spectrophotometric assays to measure glucose net flux (Pajor et al. 1989). The application of HPLC to these kinds of measurements will be especially useful for those sugars for which radiolabeled substrates are not commercially available (e.g. many of the disaccharides and trisaccharides). HPLC measurements revealed that veliger larvae of $C$. gigas have the ability to take up the monosaccharide glucose but not L-rhamnose (Fig. 2A). The disaccharide maltose was taken up from seawater at a rate similar to glucose (Fig. 2A). However, the rate of energy input into the larvae from the transport of maltose would be approximately twice that from glucose transport. Glucose enters the larva by a transport system not shared with maltose: the rate of glucose transport from $1 \mu \mathrm{M}$ is not affected by the presence of excess maltose $(200 \mu \mathrm{M})$ (Table 1$)$. This suggests that maltose is not being hydrolyzed prior to being transported as glucose monomers. Larvae of $C$. gigas also have the ability to take up the disaccharide cellobiose, the trisaccharide cellotriose, but not isomaltose, maltotriose nor isomaltotriose (Fig. 3A, B). Like bivalve larvae, veligers of the gastropod Haliotis rufescens were also found to take up glucose and maltose, but not the monosaccharide L-rhamnose, nor the trisaccharide maltotriose (Fig. 2B). Cellobiose and cellotriose were not tested with larvae of H. rufescens.

Glucose is believed to be the dominant monosaccharide in seawater (Ittekkot et al. 1981, Sakugawa \& Handa 1983) and is probably a result of oligosaccharide hydrolysis. Phytoplankton have been shown to produce $\alpha 1-4$ and $\beta 1-4$ glucans as storage products (Craigie 1974, Lewin 1974). Maltose is also used by some phytoplankton as a storage product (Patil \& Joshi 1970). The breakdown of these glucans produces smaller sugars (glucose, maltose, maltotriose) that are possibly released into the water column by exudation or upon cell lysis. Both $\beta 1-3$ and $\beta 1-4$ glucans are found in seawater and their presence has been attributed to algal blooms (Sakugawa \& Handa 1983, Sakugawa \& Nobuhiko 1985). Some of the hydrolysis products of $\beta 1$ 4 glucans are glucose, cellobiose, and cellotriose. Larvae can take up complex sugars that have 1-4 glycosidic linkages (maltose, cellobiose, cellotriose). However, larvae cannot take up isomaltose or isomaltotriose both of which have 1-6 glycosidic linkages. This suggests that the 1-6 linkage might confer a steric hindrance for transport. By having the ability to take up more complex sugars, in addition to monomers, molluscan larvae are able to utilize a greater fraction of the DOM pool as a source of nutrition.

Acknowledgements. Thanks to John McMullen of the 'Ab Lab', California, and Ken Cooper of Coast Oyster Company, Washington, for supplying larvae. One of us (J.R.W.) would like to dedicate this paper to the late Mrs Bettye Welborn. This work was supported by a grant from the National Science Foundation (OCE 860889).

\section{LITERATURE CITED}

Ahearn, G. A., Gomme, J. (1975). Transport of exogenous Dglucose by the integument of a polychaete worm (Nereis diversicolor Muller). J. exp. Biol. 62: 243-264

Craigie, J. S. (1974). Storage products. In: Stewart, D. W. P. (ed.) Algal physiology and biochemistry. Blackwell Scientific Publications, Oxford, p. 206-235

Davis, J. P.. Stephens, G. C. (1984). Uptake of free amino acids by bacteria-free larvae of the sand dollar Dendraster excentricus. Am. J. Physiol. 247: R733-R739

Dawson, R., Mopper, K. (1978). A note on the losses of mono- 
saccharides, amino sugars, and amino acids from extracts during concentration procedures. Analyt. Biochem. 84: 186-190

Ferguson, J. C. (1967). An autoradiographic study of the utilization of free exogenous amino acids by starfishes. Biol. Bull. mar. biol. Lab., Woods Hole 133: 317-329

Holst, H., Zebe, E. (1984). Absorption of volatile fatty acids from ambient water by the lugworm Arenicola marina. Mar. Biol. 80: 125-130

Ittekkot, V., Brockmann, U., Michaelis, W., Degens, E. (1981) Dissolved free and combined carbohydrates during a phytoplankton bloom in the North Sea. Mar Ecol. Prog. Ser. 4: 299-305

Jaeckle, W. B., Manahan, D. T (1989). Amino acid uptake and metabolism by larvae of Urechis caupo (Echiura), a new species in axenic culture. Biol. Bull. mar. biol. Lab., Woods Hole 176: 317-326

Johannes, R. E., Coward, S. J., Webb, K. L. (1969). Are dissolved amino acids an energy source for marine invertebrates? Comp. Biochem. Physiol. 29: 283-288

Lewin, R. A. (1974). Biochemical taxonomy. In: Stewart, D. W. P. (ed.) Algal physiology and biochemistry. Blackwell Scientific Publications, Oxford, p. 1-39

Manahan, D. T., Wright, S. H., Stephens, G. C., Rice, M. A. (1982). Transport of dissolved amino acids by the mussel, Mytilus edulis: demonstration of net uptake from natural sea water Science 215: 1253-1255

Manahan, D. T (1989). Amino acid fluxes to and from seawater in axenic veliger larvae of a bivalve (Crassostrea gigas). Mar. Ecol. Prog. Ser. 53: 247-255

Mopper, K., Dawson, R., Liebezeit, G., Ittekkot, V. (1980). The monosaccharide spectra of natural waters. Mar. Chem. 10: $55-66$

Pajor, A. M., Moon, D. A., Wright, S. H. (1989). Sodium D-

This article was presented by Professor N. D. Holland, La Jolla, California, USA. glucose cotransport in the gill of marine mussels: studies with intact tissue and brush border membrane vesicles. J. Membrane Biol. 107: 77-88

Patil, B. A., Joshi, G. V (1970). Photosynthetic studies in Ulva lactuca. Botanica mar. 13: 111-115

Sakugawa, H., Handa, N. (1983). Chemical studies of dissolved carbohydrates. J. oceanogr Soc. Jpn 39: 279-288

Sakugawa, H., Nobuhiko, H. (1985). Isolation and chemical characterization of dissolved and particulate polysaccharides in Mikawa Bay. Geochim. cosmochim. Acta 49: $1185-1193$

Schneider, E. G., Whitten, D. J. (1987). Uptake and metabolism of nucleosides by embryos of the sea urchin Strongylocentrotus purpuratus. Exp. Cell Res. 168: 1-14

Stephens, G. C. (1962). Uptake of organic material by aquatic invertebrates. I. Uptake of glucose by the solitary coral, Fungia scutaria. Biol. Bull. mar, biol. Lab., Woods Hole 123: 648-660

Stephens, G. C., Schinske, R. A. (1961). Uptake of amino acids by marine invertebrates. Limnol. Oceanogr 6: 175-181

Testerman, J. K. (1972). Accumulation of free fatty acids from sea water by marine invertebrates. Biol, Bull mar. biol. Lab., Woods Hole 142: 160-177

Watanabe, N. (1985). Amperometric detection of reducing carbohydrates in high-performance liquid chromatography using an amine-bonded column and acetonitrilewater as the eluent. J. Chromatogr 330: 333-338

Watanabe, N., Inoue, M. (1983). Amperometric detection of reducing carbohydrates in liquid chromatography. Analyt Chem. 55: 1016-1019

Williams, P. J. leB. (1975). Biological and chemical aspects of dissolved organic material in sea water In: Riley, J. P., Skirrow, G. (eds.) Chemical oceanography, Vol. 2, 2nd edn. Academic Press, New York, p. 301-363

Manuscript first received: December 10, 1989

Revised version accepted: May 28, 1990 